\title{
Solid Papillary Carcinoma: A Cytologic-Histologic Correlation of an Uncommon Breast Neoplasm
}

\section{Moira Ragazzi ${ }^{1^{*}}$ and Giuseppe Falco ${ }^{2}$}

${ }^{1}$ Pathology Unit, IRCCS Arcispedale Santa Maria Nuova Hospital, Reggio Emilia, Italy

${ }^{2}$ Breast Surgery Unit, IRCSS Arcispedale Santa Maria Nuova Hospital, Reggio Emilia, Italy

"Corresponding author: Moira Ragazzi, Pathology Unit, IRCCS-Arcispedale Santa Maria Nuova, Viale Risorgimento 8042123 Reggio Emilia, Italy, Tel: +39 0522/295657; Fax: +39 0522/296945; E-mail: moira.ragazzi@asmn.re.it

Rec date: Nov 02, 2014, Acc date: Nov 04, 2014, Pub date: Nov 06, 2014

Copyright: ( 2014 Ragazzi M, et al. This is an open-access article distributed under the terms of the Creative Commons Attribution License, which permits unrestricted use, distribution, and reproduction in any medium, provided the original author and source are credited.

\section{Description}

Cytological smear from a 79 year old women with nipple retraction. Examination with mammography was negative. Ultrasound investigation showed a well-delimited, hypoechogenic nodule, $1.2 \mathrm{~cm}$ in greatest axis.

Numerous neoplastic cells arranged in sheets (Figure 1a) and papillary structures (Figure 1b). Cells are quite monomorphic, characterized by peripherally located nuclei and disperse chromatin with inconspicuous nucleoli and abundant granular cytoplasm (Figure 1c). An intracytoplasmic vacuole can be appreciated (Figure 1c, arrow). Mucoid material is evident on May-Grunwald Giemsa stain (Figure 1d).

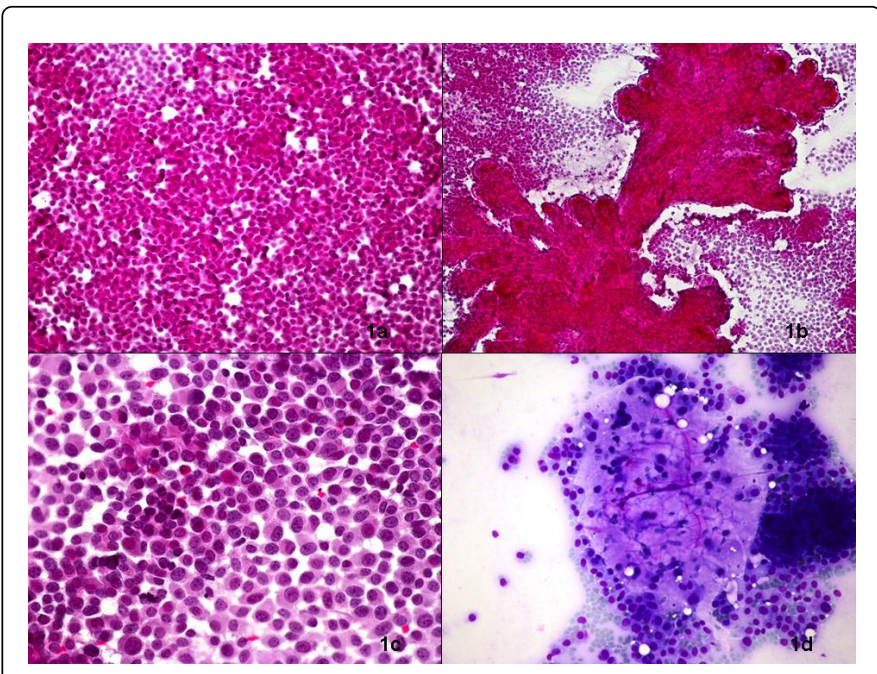

Figure 1: a) shows stained sections neoplastic cells, b) presents the papillary structures, c) shows monomorphic cells with peripherally located inconspicuous nuclei, dispersed chromatin and the abundant granular cytoplasm, d) Mucoid material visualization.

A mastectomy was performed.

Histological diagnosis: solid papillary carcinoma of the breast (Figure 2).

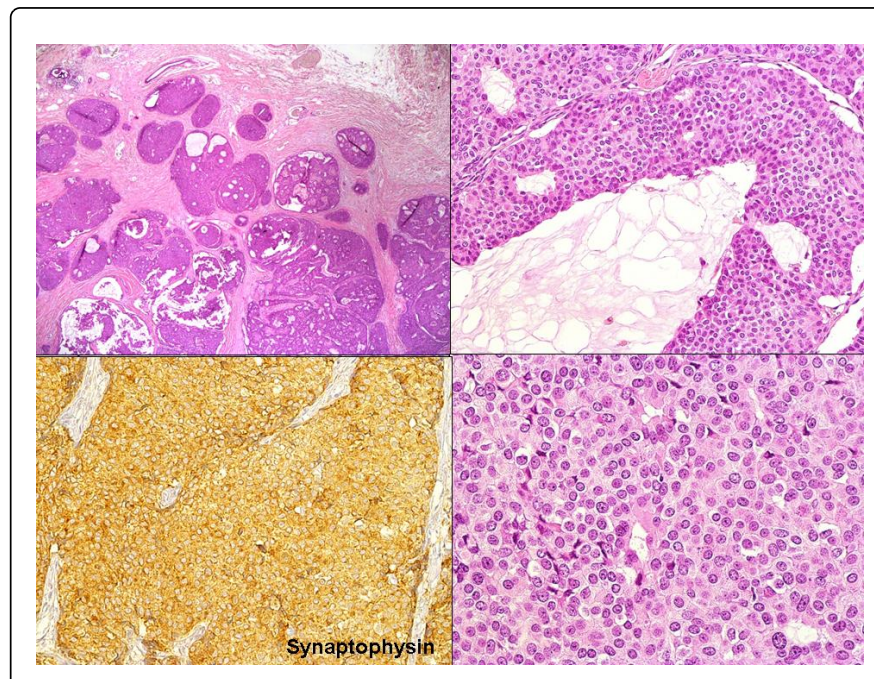

Figure 2: solid papillary carcinoma of breast.

It is a controversial entity in breast pathology. First described by Maluf and Koerner in 1995 [1] as a type of intraductal carcinoma with endocrine differentiation, precursor of type B mucinous carcinoma, it has been recently referred to as an invasive tumor with low malignant potential [2].

In the latest WHO (2012) is listed as a distinct entity, accounting for less than $1 \%$ of breast carcinoma, regarded for staging purposes as a form of in situ carcinoma [3].

\section{References}

1. Maluf HM, Koerner FC (1995) Solid papillary carcinoma of the breast. A form of intraductal carcinoma with endocrine differentiation frequently associated with mucinous carcinoma. Am J Surg Pathol 19: 1237-1244.

2. Rakha EA, Gandhi N, Climent F, van Deurzen CH, Haider SA, et al. (2011) Encapsulated papillary carcinoma of the breast: an invasive tumor with excellent prognosis. Am J Surg Pathol 35: 1093-1103.

3. Lakhani SR, Ellis IO, Schnitt SJ, Tan PH, van de Vijver MJ (2012) World Health Organization. Classification of Tumours of the Breast (4th edn), Vol. 4: Lyon, France. 